\title{
NEOPLASIA MALIGNA E DOENÇAS INFECCIOSAS: PRINCIPAIS CAUSAS DE MORTALIDADE FEMININA NA REGIÃO DO CARIRI CEARENSE NO ANO DE 2016
}

\author{
Esther de Macêdo Liral, Daniel Gonçalves Leite ${ }^{2}$; Antonio Marlos Duarte de Melo ${ }^{2}$; \\ Leyde Jenifer Dias Uchôa ${ }^{2}$; Barbara Torquato Alves ${ }^{2}$; Brenda Lacerda da Silva ${ }^{2}$; \\ Patrícia Sobral Luna Quidute ${ }^{3}$
}

Introdução: Quantificar a mortalidade por neoplasia e infecções gerais em mulheres, é um ponto muito importante para que haja conscientização para o cuidado com a saúde feminina, além de proporcionar um melhor planejamento por parte do poder público das estratégias dirigidas para diagnóstico precoce, prevenção e controle de tais agravos nessa população específica. Objetivo: Este estudo objetiva descrever a quantidade de óbitos gerados por Neoplasias em comparação aos gerados por complicações infecciosas em mulheres da região do Cariri cearense, durante todo o ano de 2016, a partir da casuística do Serviço de Verificação de Óbitos (SVO) de Barbalha-CE. Método: Foi realizada análise retrospectiva de 836 prontuários de pacientes examinados no SVO no período citado. Foram incluídas apenas aquelas mulheres que possuíam neoplasia ou afecções infecciosas como principal causa base ou final do seu óbito. Foram excluídos os neonatos. O índice de mortalidade foi dividido por faixas etárias tendo em vista a descrição de diferentes resultados para cada uma delas. Por ser o único SVO da região e por atender a sete municípios, incluindo os três mais populosos (Juazeiro do Norte, Crato e Barbalha), a casuística é representativa da população do Cariri cearense. Resultados: Dos 836 prontuários do período estudado, 327 são de mulheres selecionadas para o estudo. Na faixa etária de 1 a 20 anos foram contabilizados 4 (1.2\%) óbitos por Infecções e 0 pôr neoplasias. Na faixa de 21 a 40 anos foram verificados 13(3.9\%) óbitos, 11 por patologias infecciosas e 2 por neoplasias. De 41 a 60 anos foram quantificadas $23(7.0 \%)$ mortes, sendo que 15 por infecções e 8 por neoplasias em geral. Nas mulheres entre 61 e 80 anos foram verificados $40(12.2 \%)$ óbitos, 27 por patologias infecciosas e 13 por neoplasias. $\mathrm{Na}$ faixa etária acima dos 80 anos foram encontradas 49(14.9\%) mortes, onde 34 foram por infecções e 15 por neoplasias. Conclusão: No total, foram quantificados 129(39.4\%) óbitos, sendo 37 causadas por Neoplasias e 92 por patologias infecciosas, esse perfil de mortalidade demonstra o grande grupo dessas doenças como principal causa de morte nessa população feminina, principalmente com o avanço da idade, demonstrando a necessidade de priorizar a prevenção, diagnóstico precoce e controle dessas doenças e de seus fatores associados para a promoção da saúde desse grupo especifico no Cariri.

Palavras Chave: Mortalidade; Neoplasias; Infecções; Saúde da mulher.

\footnotetext{
1;2 Discente do curso de Medicina da Faculdade de Medicina Estácio de Juazeiro do Norte-CE

${ }^{3}$ Médica Radiologista. Instituto de Mama do Cariri no Juazeiro do Norte-CE;

Autor correspondente: esther_macedo@hotmail.com
}

17 Id on Line Rev. Mult. Psic. V.12, N. 40. 2018 - ISSN 1981-1179 EDIÇÃO ESPECIAL: I CURSO DE ONCOLOGIA DO CARIRI / II JORNADA DE PESQUISA QUANTI-QUALITATIVA EM ONCOLOGIA. JUAZEIRO DO NORTE, 05 A 10 DE MARÇO DE 2018. Edição eletrônica em http://idonline.emnuvens.com.br/id 